\title{
Association between oncogenic status and risk of venous thromboembolism in patients with non-small cell lung cancer
}

\author{
Feifei Dou ${ }^{1 \dagger}$, Huiqiao $\mathrm{Li}^{1 \dagger}$, Min Zhu', Lirong Liang ${ }^{2}$, Yuan Zhang ${ }^{1}$, Jiawen Yi ${ }^{1}$ and Yuhui Zhang ${ }^{1 *}$
}

\begin{abstract}
Background: Preclinical data suggest that oncogene (EGFR and KRAS) events regulate tumor procoagulant activity. However, few studies have prospectively investigated the clinical relevance between the presence of EGFR or KRAS mutations and occurrence of venous thromboembolism(VTE) in patients with non-small cell lung cancer (NSCLC).

Methods: A total of 605 Chinese patients with newly diagnosed NSCLC were included and were followed for a maximum period of 4.5 years. EGFR and KRAS mutations were determined by amplification refractory mutation system polymerase chain reaction method at inclusion. The main outcome was objectively confirmed VTE.

Results: Of the 605 patients, 40.3\% (244) had EGFR mutations and 10.2\% (62) of patients had KRAS mutations. In multivariable analysis including age, sex, tumor histology, tumor stage, performance status, EGFR and KRAS status, EGFR wild-type (sub-distribution hazard ratio 1.81,95\% confidence interval 1.07-3.07) were associated with the increased risk of VTE. In competing risk analysis, the probability of developing VTE was 8.3\% in those with and 13. 2\% in those without EGFR mutations after 1 year; after 2 years, the corresponding risks were 9.7 and 15.5\% (Gray test $P=0.047$ ).
\end{abstract}

Conclusions: EGFR mutations have a negative association with the risk of VTE in Chinese patients with NSCLC.

Keywords: Non-small cell lung cancer, Venous thromboembolism, Mutation, Oncogene, Epidermal growth factor receptor, Kitten rat sarcoma

\section{Background}

Venous thromboembolism (VTE) is a frequent complication seen in patients with non-small cell lung cancer (NSCLC) [1-3] and is associated with poor quality of life and worse prognosis [4-6]. The mechanisms responsible for VTE in patients with cancer, however, are not fully understood.

Tissue factor (TF) is the primary cellular initiator of blood coagulation and a modulator of angiogenesis and metastasis in cancer $[7,8]$. Tumor cells frequently overexpress TF and spontaneously release TF-positive microparticles into the blood, which are small membrane vesicles that are highly procoagulant [9-11]. Further,

\footnotetext{
* Correspondence: zhangyhcy@163.com

†Equal contributors

${ }^{1}$ Department of Respiratory and Critical Care Medicine, Beijing Chao-Yang Hospital, Capital Medical University, Beijing Institute of Respiratory Medicine, Beijing 100020, China

Full list of author information is available at the end of the article
}

preclinical data suggest that genetic links (activation of oncogenes such as EGFR, RAS or MET, and inactivation of tumor suppressor genes such as p53 or PTEN) directly induce the expression of genes controlling hemostasis (such as TF gene), which can extend systemically hypercoagulability and cancer progression [12-19]. Still, little is known about the clinical relevance of these links between oncogenic status and the risk of VTE in NSCLC.

Both EGFR and KRAS mutations are most frequent oncogenic driver mutations for NSCLC [20, 21]. The frequency of oncogenic mutations was associated with race $[22,23]$. Asian patients had the relatively higher rate of EGFR mutations, but the lower rate of KRAS mutations than Caucasian $[24,25]$. In the prospective observational study, we examined associations between the presence of EGFR or KRAS mutations and occurrence of VTE in Chinese patients with newly diagnosed NSCLC. 


\section{Methods}

\section{Study populations}

Consecutive patients with newly diagnosed NSCLC between May 2012 and May 2017 who met the following inclusion criteria were included in the prospective observational study: histological confirmation of diagnosis; identification of EGFR and KRAS gene mutations; willingness to participate; and provided written informed consent. The exclusion criteria were as follows: any surgery, chemotherapy, or radiotherapy within the past 3 months before recruitment;a history of VTE (VTE diagnosis at least 3 months prior to recruitment) and the continuous use of anticoagulant drugs. The patients were followed up prospectively for a maximum 4.5 years' observation period until the occurrence of death, loss of follow-up, withdrawal of consent, or the censure date (July 1, 2017).

\section{Diagnosis and classification of VTE}

All the included patients were instructed about the symptoms of VTE and requested to report when such symptoms occurred, but no active screening for VTE was conducted. In case of symptoms, objective imaging methods were used to confirm or exclude the diagnosis of VTE. Deep vein thrombosis (DVT) events were confirmed by venous ultrasound imaging or a computed tomography venous angiogram. Pulmonary embolism (PE) events were confirmed by a computed tomography pulmonary angiogram or a ventilation-perfusion scan (if patients had renal insufficiency or allergy to contrast). In patients who had died during follow-up, death certificates and autopsy-reports, if available, were reviewed to establish or exclude the diagnosis of fatal PE or VTE. Then, all VTE events were presented to an independent adjudication committee including experts in the fields of angiology and radiology. The adjudication committee confirmed or excluded the diagnosis. In addition, patients with no symptoms of VTE underwent clinical surveillance every 2 or 3 months depending on the therapy. Accidentally detected VTE was considered as an event, if the committee determined that the event was of clinical significance.

\section{Laboratory methods}

At the time of study entry, DNA of tumor tissues was screened for gene mutations. Tumour biopsy specimens were formalin-fixed and paraffin-embedded (FFPE) for histology and mutation analysis. Pathological assessment of serial FFPE tissue sections and clinical disease staging was according to the 2004 World Health Organization classification guidelines and the TNM staging system of the International Association for the Study of Lung Cancer (version 7). Isolation of genomic DNA from FFPE tissue for amplification refractory mutation system polymerase chain reaction (ARMS-PCR) mutation analysis was performed using the FFPE DNA Kit and DNA purification spin columns (Beijing ACCB Biotech Ltd). ARMS-PCR for tissue mutation detection was performed using the Human EGFR and KRAS Gene Mutations Fluorescence Polymerase Chain Reaction Diagnostic Kit (Beijing ACCB Biotech Ltd). Three-step PCR cycling was performed on the real-time Mx3000P instrument (Agilent, Santa Clara, CA, USA) with the following settings: $95{ }^{\circ} \mathrm{C}$ for $10 \mathrm{~min}, 40$ cycles of $95{ }^{\circ} \mathrm{C}$ for $15 \mathrm{~s}$, and $60{ }^{\circ} \mathrm{C}$ for $1 \mathrm{~min}$. Mutation detection levels were assessed by threshold cycle $(\mathrm{Ct})$ values with strong positives $(\mathrm{Ct}<35)$ equivalent to mutation levels of $>5 \%$, and weak positives $(35 \leq \mathrm{Ct}<38)$ equivalent to levels of 1 to $5 \%$. Negative samples were defined with a $\mathrm{Ct}$ value $\geq 38$.

\section{Statistical methods}

Continuous variables were described by median and interquartile range. For the categorical variables, the percentages of patients in each category were calculated. The clinical characteristics were compared between subgroups of patients with and without VTE using the chisquare test or Fisher's exact test, as appropriate. FineGray regression analyses were used for calculating the risk factors of VTE. A competing risk analysis was performed to determine the cumulative incidence of VTE with death considered a competing event. Grey's test was used to identify statistically significant differences between patients with different statuses of oncogenic mutations. A value of $P<0.05$ was considered statistically significant. $\mathrm{R}$ statistical software was used to perform the competing risk analysis and Fine-Gray regression analyses. SPSS statistical software (Version 22.0; IBM, Armonk, NY, USA) was used for all other analyses. The study was reviewed by an epidemiologist and conformed to all the items of the Strobe statement.

\section{Results \\ Patient characteristics}

A total of 746 consecutive patients with newly diagnosed NSCLC were enrolled in this study. Sixty two patients were excluded because they lacked adequate material for detection of EGFR and KRAS mutations. Twenty patients were excluded because they had a history of DVT or PE more than 3 months before recruitment. Another 59 patients were excluded because they lacked complete information on follow-up. In the end, 605 eligible patients were included in our study (Fig. 1).

The 605 included NSCLC patients had a median age of 62.0 years, and $58.2 \%$ of the patients were males. The population consisted of 471 patients with adenocarcinoma $(77.9 \%)$ and 134 patients with nonadenocarcinoma (22.1\%). There were 417 stage IV patients (68.9\%) with 


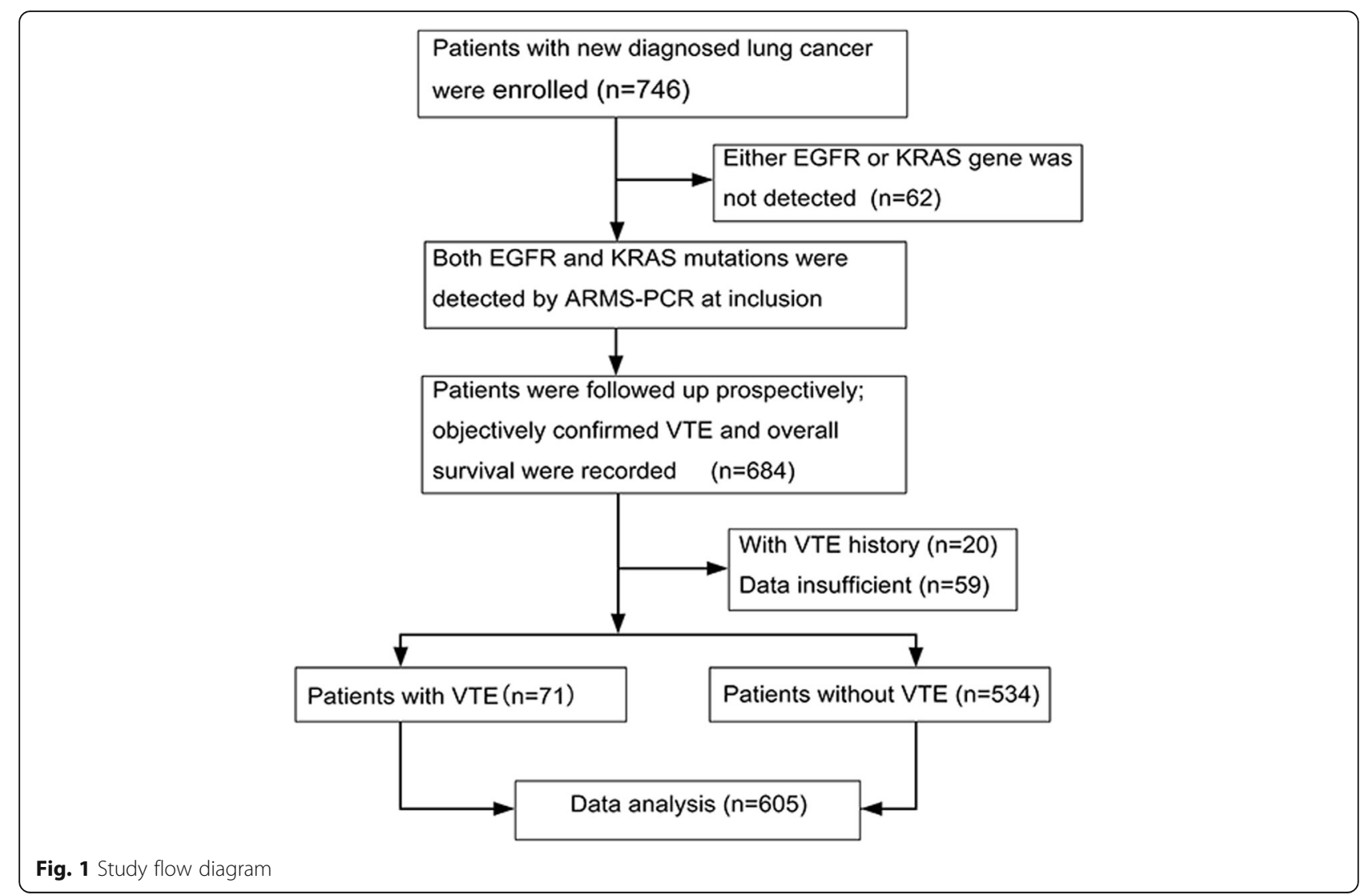

distant metastases, of which 7 were symptomatic brain metastases, and 17 were asymptomatic brain metastases. Furthermore, 24 of the patients had symptomatic bone metastases and 117 of the patients had asymptomatic bone metastases. An additional 29 patients presented with both brain and bone metastases, 13 of which were symptomatic. Patients with PS $=2-3$ were considered to be a particularly frail group, with a total of 181 patients. Among them, there were 162 patients with $\mathrm{PS}=2,19$ patients with $\mathrm{PS}=3$. The baseline demographic and clinical characteristics of the investigated study population are listed (Table 1).

\section{Development of VTE}

A total of 243 of the 605 patients (40.2\%) died during follow-up, and 362 were alive at the censure date (59. $8 \%$ ). Of those who died during follow-up, 32 of them had localized disease while the other 211 had distant metastasis at the time of recruitment. Overall, 71 of the 605 patients $(11.7 \%)$ experienced a VTE event from date of diagnosis to date of last follow-up. Of those, in 44 patients (7.3\%) DVT alone developed (including the lower extremity, upper extremity, neck, or pelvis DVT), PE alone developed in 7 patients $(1.1 \%$, including 3 fatal PE), and both DVT and PE developed in 20 patients $(3.3 \%)$ (Table 2$)$.

\section{Mutations and risk of VTE}

Both EGFR (exons 18, 19, 20, and 21) and KRAS (codons 12 and 13) mutations were determined by ARMSPCR at inclusion. Of the 605 patients, 40.3\% (244) had EGFR mutations and $10.2 \%$ (62) of patients had KRAS mutations. The types of EGFR and KRAS mutations and frequency of VTE are listed (Table 3). There was no significant association between mutation type and risk of VTE (Table 3).

Of the 244 patients with EGFR mutations, VTE developed in 22 (9.0\%), whereas VTE developed in 49 of 361 patients (13.6\%) with EGFR wild-type. After 1 year, the probability for development of VTE was $8.3 \%$ in those with and $13.2 \%$ in those without EGFR mutations; after 2 years, the corresponding risks were 9.7 and $15.5 \%$ (Gray test $P=0.047$ ) (Fig. 2a). Moreover, of the 62 patients with KRAS mutated type, VTE developed in 10 (16.1\%), whereas VTE developed in 61 of 543 patients (11.2\%) with KRAS wild-type. After 1 year, the probability for development of VTE was $16.1 \%$ in those with and $10.6 \%$ in those without KRAS mutations; after 2 years, the corresponding risks were $18.8 \%$ and $12.4 \%$, respectively (Gray test $P=0.180$ ) (Fig. $2 b$ ).

Subsequently, we performed a Fine-Gray regression model that included the age, sex, different tumor histology (adenocarcinoma vs. nonadenocarcinoma), tumor 
Table 1 Baseline demographic and clinical characteristics of the study population

\begin{tabular}{|c|c|c|}
\hline Characteristic & $\begin{array}{l}\text { All patients } \\
(n=605)(\%)\end{array}$ & $\begin{array}{l}\text { Patients with VTE } \\
(n=71)(\%)\end{array}$ \\
\hline Median age, years & 62 & 60 \\
\hline 25th-75th percentile & $55-69$ & $51-69$ \\
\hline$<60$ & $237(39.2)$ & $32(45.1)$ \\
\hline$\geq 60$ & $368(60.8)$ & $39(54.9)$ \\
\hline \multicolumn{3}{|l|}{ Sex } \\
\hline Male & $352(58.2)$ & $40(56.3)$ \\
\hline Female & $253(41.8)$ & $31(43.7)$ \\
\hline \multicolumn{3}{|l|}{ ECGO PS } \\
\hline $0-1$ & $424(70.1)$ & $41(57.7)$ \\
\hline $2-3$ & $181(29.9)$ & $30(42.3)$ \\
\hline \multicolumn{3}{|l|}{ Tumor histology } \\
\hline Adenocarcinoma & $471(77.9)$ & $62(87.3)$ \\
\hline Non-adenocarcinoma & $134(22.1)$ & $9(12.7)$ \\
\hline Squamous cell carcinoma & $125(20.7)$ & $8(11.3)$ \\
\hline Other NSCLC & $9(1.4)$ & $1(1.4)$ \\
\hline \multicolumn{3}{|l|}{ Tumor Stage } \\
\hline Localized & $137(22.6)$ & $16(22.5)$ \\
\hline Distant metastasis & $468(77.4)$ & $55(77.5)$ \\
\hline \multicolumn{3}{|l|}{ EGFR gene } \\
\hline Wild & $361(59.7)$ & $49(69.0)$ \\
\hline Mutated & $244(40.3)$ & $22(31.0)$ \\
\hline \multicolumn{3}{|l|}{ KRAS gene } \\
\hline Wild & $543(89.8)$ & $61(85.9)$ \\
\hline Mutated & $62(10.2)$ & $10(14.1)$ \\
\hline \multicolumn{3}{|c|}{ Treatment during observation period } \\
\hline Other treatment without TKI & $220(36.4)$ & $27(38.0)$ \\
\hline Other treatment with TKI & $96(15.9)$ & $13(18.3)$ \\
\hline TKI alone & $141(23.3)$ & $11(15.5)$ \\
\hline Chemotherapy alone & $148(24.5)$ & $20(28.2)$ \\
\hline
\end{tabular}

Abbreviations: ECOG Eastern Cooperative Oncology Group, PS performance status, EGFR epidermal growth factor receptor, KRAS kitten rat sarcoma, NSCLC non-small cell lung cancer, TKI Tyrosine Kinase Inhibitor

stage (localized stage vs. distant metastasis), Eastern Cooperative Oncology Group performance status (0-1 vs. 2-3), EGFR and KRAS mutations (mutated vs. wildtype) to identify the factors associated with VTE. Adenocarcinoma [sub-distribution hazard ratio (SHR) 2.40, 95\% confidence interval (CI) $1.11-5.19, P=0.027]$, poor performance status (SHR 1.91, 95\% CI 1.18-3.09, $P$ $=0.008$ ), and EGFR wild-type (SHR 1.81, 95\% CI 1.07-3.07, $P=0.028)$ were associated with an increased risk of VTE. Age, sex, KRAS gene and tumor stage were not associated with the development of VTE (Table 4).
Table 2 Incidence and types of VTE in NSCLC

\begin{tabular}{ll}
\hline Type/Site of VTE & No. of patients (\%) \\
\hline Total episodes & $71(11.7)$ \\
DVT alone & $44(7.3)$ \\
Upper extremity and neck & $10(1.6)$ \\
Lower extremity and pelvis & $32(5.3)$ \\
Upper extremity and lower extremity & $2(0.3)$ \\
PE alone & $7(1.1)$ \\
Segmental/subsegmental & $4(0.6)$ \\
Above segmental & $3(0.5)$ \\
DVT and PE combined & $20(3.3)$ \\
Lower extremity, pelvis DVT and segmental PE & $13(2.1)$ \\
Upper extremity, pelvis DVT and above & $1(0.2)$ \\
segmental PE & \\
Lower extremity, pelvis DVT and above & $4(0.6)$ \\
segmental PE & \\
Upper extremity, lower extremity DVT and & $2(0.3)$ \\
segmental PE &
\end{tabular}

Abbreviations: DVT deep vein thrombosis, NSCLC non-small cell lung cancer, $P E$ pulmonary embolism, VTE venous thromboembolism

Table 3 Types of EGFR and KRAS mutations and frequency of VTE

\begin{tabular}{|c|c|c|}
\hline \multirow[t]{2}{*}{ Mutation type } & Number & VTE \\
\hline & $(n=306)(\%)$ & $(n=32)(\%)$ \\
\hline EGFR exon 18 mutation only & $3(1.0)$ & $0(0.0)$ \\
\hline EGFR exon 19 deletion only & $106(34.6)$ & $9(28.1)$ \\
\hline EGFR exon 20 T790 M only & $0(0.0)$ & $0(0.0)$ \\
\hline EGFR exon $20 \mathrm{S768l}$ only & $4(1.3)$ & $0(0.0)$ \\
\hline EGFR exon 20 insertion only & $11(3.6)$ & $0(0.0)$ \\
\hline EGFR exon 21 L858R only & $106(34.6)$ & $12(37.5)$ \\
\hline EGFR exon 21 L861Q only & $7(2.3)$ & $0(0.0)$ \\
\hline EGFR exon $18+$ exon 21 L861Q & $1(0.3)$ & $0(0.0)$ \\
\hline EGFR exon $18+$ exon $20 \mathrm{~S} 768 \mathrm{l}$ & $2(0.6)$ & $1(3.1)$ \\
\hline EGFR exon $19+$ exon 21 L861Q & $1(0.3)$ & $0(0.0)$ \\
\hline EGFR exon $19+$ exon 20 T790 M & $1(0.3)$ & $0(0.0)$ \\
\hline EGFR exon 20 T790 M + exon 21 L858R & $1(0.3)$ & $0(0.0)$ \\
\hline EGFR exon 20 S768I + exon 21 L858R & $1(0.3)$ & $0(0.0)$ \\
\hline KRAS codon G12C(34G > T) only & $19(6.2)$ & $5(15.6)$ \\
\hline KRAS codon G12S(34G > A) only & $2(0.6)$ & $2(6.3)$ \\
\hline KRAS codon G12R(34G > C) only & $5(1.6)$ & $0(0.0)$ \\
\hline KRAS codon G12 V(35G > T) only & $14(4.6)$ & $3(9.4)$ \\
\hline KRAS codon G12D(35G > A) only & $12(3.9)$ & $0(0.0)$ \\
\hline KRAS codon G12A(35G > C) only & $9(2.9)$ & $0(0.0)$ \\
\hline KRAS codon G13D(38G > A) only & $0(0.0)$ & $0(0.0)$ \\
\hline $\begin{array}{l}\text { KRAS codon } G 12 R(34 G>C)+\text { codon } \\
G 12 D(35 G>A)\end{array}$ & $1(0.3)$ & $0(0.0)$ \\
\hline
\end{tabular}

Abbreviations: EGFR epidermal growth factor receptor, KRAS kitten rat sarcoma 

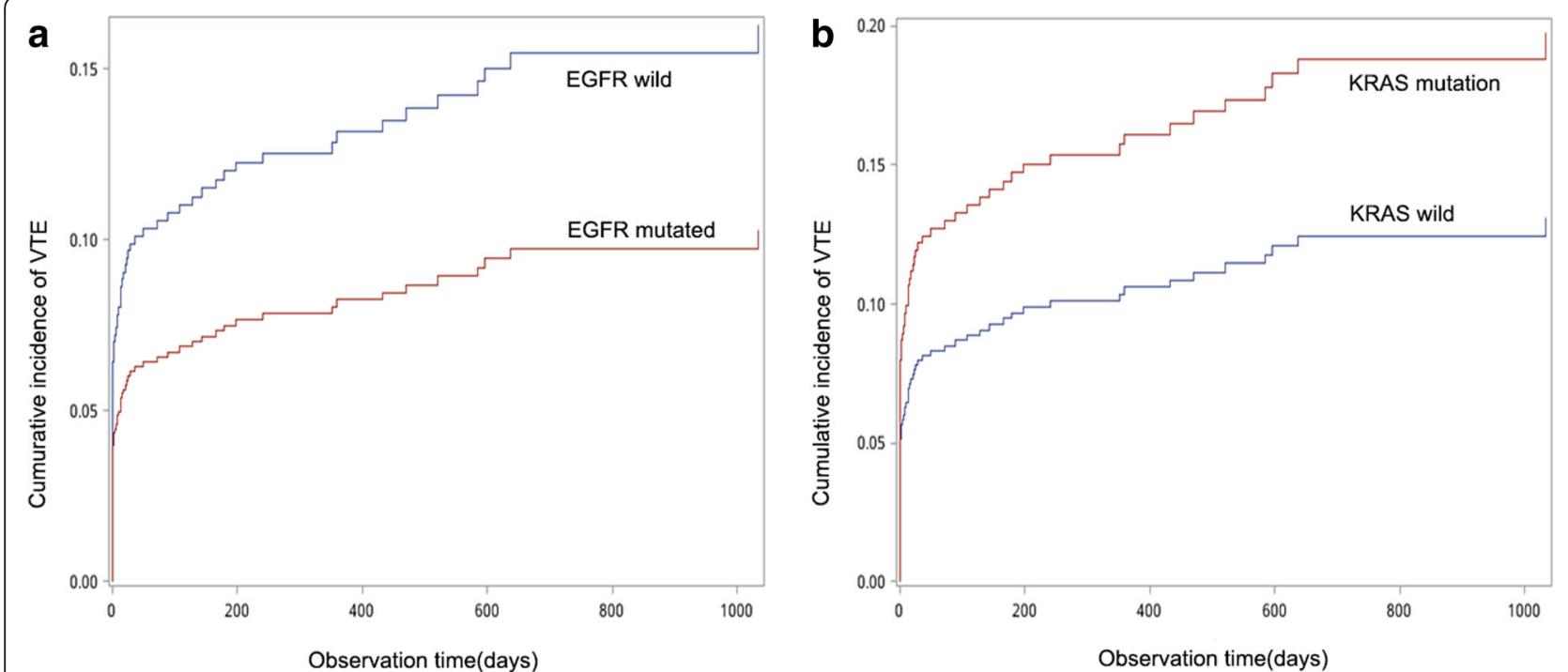

Fig. 2 Competing risk analysis. a. The cumulative incidence of venous thromboembolism (VTE) in non-small cell lung cancer (NSCLC) patients with and without EGFR mutations ( $P=0.047$ ) assessed by the competing risk analysis. $\mathbf{b}$. The cumulative incidence of venous thromboembolism (VTE) among non-small cell lung cancer (NSCLC) patients with and without KRAS mutations $(P=0.180)$ assessed by the competing risk analysis

Table 4 Factors associated with increased risk of VTE in patients with NSCLC

\begin{tabular}{|c|c|c|c|}
\hline Patients Group & SHR & $95 \% \mathrm{Cl}$ & $P$-value \\
\hline \multicolumn{4}{|l|}{ Tumor histology (\%) } \\
\hline Non-adenocarcinoma & 1 & & \\
\hline Adenocarcinoma & 2.40 & $1.11-5.19$ & 0.027 \\
\hline \multicolumn{4}{|l|}{ ECOG PS } \\
\hline $0-1$ & 1 & & \\
\hline $2-3$ & 1.91 & $1.18-3.09$ & 0.008 \\
\hline \multicolumn{4}{|l|}{ EGFR gene } \\
\hline Mutated & 1 & & \\
\hline Wild & 1.81 & $1.07-3.07$ & 0.028 \\
\hline \multicolumn{4}{|l|}{ Age } \\
\hline$\geq 60$ & 1 & & \\
\hline$<60$ & 1.27 & $0.79-2.02$ & 0.324 \\
\hline \multicolumn{4}{|l|}{ Sex } \\
\hline Female & 1 & & \\
\hline Male & 1.03 & $0.63-1.66$ & 0.920 \\
\hline \multicolumn{4}{|l|}{ Tumor Stage } \\
\hline Distant metastasis & 1 & & \\
\hline Localized & 1.18 & $0.67-2.07$ & 0.569 \\
\hline \multicolumn{4}{|l|}{ KRAS gene } \\
\hline Wild & 1 & & \\
\hline Mutated & 1.10 & $0.52-2.32$ & 0.814 \\
\hline
\end{tabular}

Abbreviations: Cl confidence interval, ECOG Eastern Cooperative Oncology Group, SHR Sub-distribution hazard ratio, NSCLC non-small cell lung cancer, PS performance status, VTE venous thromboembolism

*The variables were entered into the Fine-Gray regression model and included age, gender, ECOG PS (0-1 vs. 2-3), EGFR (mutated vs. wild), KRAS (mutated vs. wild), tumor histology (adenocarcinoma vs. nonadenocarcinoma), and tumor stage (localized stage vs. distant metastasis). All variables were shown in the table

\section{Discussion}

In the prospective observational study population of Chinese patients with newly diagnosed NSCLC, the presence of EGFR mutations might decrease the risk of VTE, whereas KRAS mutations were not significantly associated with VTE risk.

\section{EGFR status and risk of VTE}

The assessment of whether oncogenic mutations affect the risk of thrombosis has been a focus of preclinical research and clinical study. Our study revealed that the risk of VTE was 1.81 (95\% CI of 1.07 to 3.07) higher in patients with EGFR wild compared to those with EGFR mutated. Preclinical data showed that amplification of EGFR or mutated EGFR vIII induces the overexpression of TF by cancer cells $[14,15]$. The increase in TF may constitute a direct link between thrombosis risk and oncogene expression in patients with cancers [8]. We assumed that EGFR mutations (exons 18, 19, 20, and 21) might decrease the expression of TF, which reduces tumor procoagulant activity and the incidence of VTE. However, previous three studies reported no association between EGFR gene status and VTE risk in patients with NSCLC [26-28]. The possible explanations of different findings were that previous studies used retrospective design and included patients from different race population.

\section{KRAS status and risk of VTE}

Limited preclinical data suggest that KRAS mutational status of the tumor represents a plausible clinical link to systemic hypercoagulability in cancer patients $[12,13]$. 
Conflicting results, however, have been reported for KRAS mutations in previous clinical studies. In our study, KRAS mutations were not independently associated with the risk of VTE in NSCLC patients. This finding was in agreement with some studies [26, 27]. However, the finding of our study was in disagreement with a published report on metastatic colorectal cancer [29]. This difference was likely because our study population consisted of NSCLC patients who had different biological characteristics. The risk of KRAS status may be weakened due to lower incidences of KRAS mutations in NSCLC than in metastatic colorectal cancer. Corrales-Rodriguez [28]found a correlation between KRAS mutation and increased risk of VTE among patients with NSCLC in a retrospective casecontrol study. The possible explanations of different findings were that our study had prospective design and investigated a Chinese population with lower KRAS mutations.

\section{Other factors and risk of VTE}

The Fine-Gray regression analyses showed two additional factors related to the occurrence of VTE. The first factor is histological type. In our study, patients with adenocarcinoma had a 2.40-fold higher risk of VTE than patients with non-adenocarcinoma (95\% CI of 1 . 11-5.19), which is in agreement with previous studies $[30,31]$. Similar results were observed in studies of PE in patients with lung cancer $[2,32]$. The second factor is performance status. A previous study showed that poor performance status was correlated with increased risk of thrombosis [33]. Similarly, our study revealed a 1.91-fold higher risk of VTE in patients with poor performance status compared to those with better performance status (95\% CI of 1.18-3.09), which is in agreement with the previous study. We found no association between age, sex or tumor stage with the occurrence of VTE.

\section{Limitations}

Our study has several limitations. Although we included a large number of NSCLC patients in this prospective cohort study, the number of patients with KRAS mutations is still relatively low. Moreover, we followed our patients carefully at regular intervals and concentrated on the most clinically relevant symptomatic VTE events in our study, but we did not screen for VTE, which possibly missed asymptomatic VTE. Finally, only common KRAS (codons 12 and 13) mutations were detected, while rare KRAS mutations might be missed.

\section{Conclusions}

The presence of EGFR mutations was associated with decreased risk of VTE, and the analysis of EGFR status might be helpful for identifying VTE risk for NSCLC.
Because the number of patients with KRAS mutations is relatively low, the link between KRAS mutations and VTE needs to be elucidated in further large-scale prospective studies.

\section{Abbreviations \\ ARMS-PCR: Amplification refractory mutation system polymerase chain reaction; Cl: Confidence interval; DVT: Deep vein thrombosis; ECOG: Eastern cooperative oncology group; EGFR: Epidermal growth factor receptor; FFPE: Formalin-fixed and paraffin-embedded; HR: Hazard ratio; KRAS: Kitten rat sarcoma; NSCLC: Non-small cell lung cancer; PE: Pulmonary embolism; PS: Performance status; TF: Tissue factor; VTE: Venous thromboembolism}

\section{Acknowledgments}

The authors would like to thank the members of the independent adjudication committee (Yuanhua Yang, MD, PhD; Lei Zhang, MD; and Zhanhong Ma, MD) for the evaluation of VTE in the study.

\section{Funding}

This study was supported in part by grants from the National Natural Science Foundation of China (Grant No. 31570890 and 31770961), and in part by the Wu Jieping Medical Foundation (Grant No. 320.6750.14286).

Availability of data and materials

Data were collected from all the patients. The datasets used and analyzed during the current study are available from the corresponding author on reasonable request.

\section{Authors' contributions}

FFD and MZ were responsible for data collection and statistical analyses. HQL was responsible for patient enrollment and data collection. LRL was responsible for statistical analyses. YZ and JWY were responsible for data collection. YHZ was responsible for study design, patient enrollment, statistical analyses, and writing of the manuscript. All authors read and approved the final manuscript.

Ethics approval and consent to participate

This study was approved by the Ethics Committees of Beijing Chao-Yang Hospital of Capital Medical University (No. 2009-4). All patients were willing to participate and provided written informed consent.

\section{Competing interests}

The authors declare that they have no competing interests.

\section{Publisher's Note}

Springer Nature remains neutral with regard to jurisdictional claims in published maps and institutional affiliations.

\section{Author details}

'Department of Respiratory and Critical Care Medicine, Beijing Chao-Yang Hospital, Capital Medical University, Beijing Institute of Respiratory Medicine, Beijing 100020, China. ${ }^{2}$ Department of Clinical Epidemiology, Beijing Chao-Yang Hospital, Capital Medical University, Beijing 100020, China.

Received: 20 November 2017 Accepted: 26 April 2018

Published online: 09 May 2018

References

1. Walker AJ, Baldwin DR, Card TR, Powell HA, Hubbard RB, Grainge MJ. Risk of venous thromboembolism in people with lung cancer: a cohort study using linked UK healthcare data. Br J Cancer. 2016;115:115-21.

2. Z Zhang Y, Yang Y, Chen W, Guo L, Liang L, Zhai Z, Wang C. Prevalence and associations of VTE in patients with newly diagnosed lung cancer. Chest. 2014;146:650-8

3. Christensen TD, Vad H, Pedersen S, Hvas AM, Wotton R, Naidu B, Larsen TB. Venous thromboembolism in patients undergoing operations for lung cancer: a systematic review. Ann Thorac Surg. 2014;97:394-400.

4. Hisada Y, Geddings JE, Ay C, Mackman N. Venous thrombosis and cancer: from mouse models to clinical trials. J Thromb Haemost. 2015;13:1372-82. 
5. Connolly GC, Dalal M, Lin J, Khorana AA. Incidence and predictors of venous thromboembolism (VTE) among ambulatory patients with lung cancer. Lung Cancer. 2012;78:253-8.

6. Chew HK, Wun T, Harvey D, Zhou H, White RH. Incidence of venous thromboembolism and its effect on survival among patients with common cancers. Arch Intern Med. 2006;166:458-64.

7. Han X, Guo B, Li Y, Zhu B. Tissue factor in tumor microenvironment: a systematic review. J Hematol Oncol. 2014;7:54.

8. Rickles FR, Patierno S, Fernandez PM. Tissue factor, thrombin, and cancer. Chest. 2003;124:58S-68S

9. Geddings JE, Mackman N. Tumor-derived tissue factor-positive microparticles and venous thrombosis in cancer patients. Blood. 2013;122: 1873-80.

10. Nomura S, Niki M, Nisizawa T, Tamaki T, Shimizu M. Microparticles as biomarkers of blood coagulation in Cancer. Biomark Cancer. 2015;7:51-6.

11. Mege D, Mezouar S, Dignat-George F, Panicot-Dubois L, Dubois C. Microparticles and cancer thrombosis in animal models. Thromb Res. 2016; 140(Suppl 1):S21-6.

12. Rao B, Gao Y, Huang J, Gao X, Fu X, Huang M, Yao J, Wang J, Li W, Zhang J, Liu H, Wang L, Wang J. Mutations of p53 and K-ras correlate TF expression in human colorectal carcinomas: TF downregulation as a marker of poor prognosis. Int J Color Dis. 2011;26:593-601.

13. Yu JL, May L, Lhotak V, Shahrzad S, Shirasawa S, Weitz JI, Coomber BL, Mackman N, Rak JW. Oncogenic events regulate tissue factor expression in colorectal cancer cells: implications for tumor progression and angiogenesis. Blood. 2005;105:1734-41.

14. Magnus N, Garnier D, Rak J. Oncogenic epidermal growth factor receptor up-regulates multiple elements of the tissue factor signaling pathway in human glioma cells. Blood. 2010;116:815-8.

15. Rong Y, Belozerov VE, Tucker-Burden C, Chen G, Durden DL, Olson JJ, Van Meir EG, Mackman N, Brat DJ. Epidermal growth factor receptor and PTEN modulate tissue factor expression in glioblastoma through JunD/activator protein-1 transcriptional activity. Cancer Res. 2009;69:2540-9.

16. Provencal M, Labbe D, Veitch R, Boivin D, Rivard GE, Sartelet H, Robitaille $Y$, Gingras D, Beliveau R. C-met activation in medulloblastoma induces tissue factor expression and activity: effects on cell migration. Carcinogenesis. 2009;30:1089-96.

17. Boccaccio C, Comoglio PM. Genetic link between cancer and thrombosis. J Clin Oncol. 2009;27:4827-33.

18. Regina S, Rollin J, Blechet C, lochmann S, Reverdiau P, Gruel Y. Tissue factor expression in non-small cell lung cancer: relationship with vascular endothelial growth factor expression, microvascular density, and K-ras mutation. J Thorac Oncol. 2008;3:689-97.

19. Regina S, Valentin JB, Lachot S, Lemarie E, Rollin J, Gruel Y. Increased tissue factor expression is associated with reduced survival in non-small cell lung cancer and with mutations of TP53 and PTEN. Clin Chem. 2009;55:1834-42.

20. Chapman AM, Sun KY, Ruestow P, Cowan DM, Madl AK. Lung cancer mutation profile of EGFR, ALK, and KRAS: meta-analysis and comparison of never and ever smokers. Lung Cancer. 2016;102:122-34.

21. Kawaguchi T, Koh Y, Ando M, Ito N, Takeo S, Adachi H, Tagawa T, Kakegawa S, Yamashita M, Kataoka K, Ichinose Y, Takeuchi Y, Serizawa M, Tamiya A, Shimizu S, Yoshimoto N, Kubo A, Isa S, Saka H, Matsumura A. Prospective analysis of oncogenic driver mutations and environmental factors: Japan molecular epidemiology for lung Cancer study. J Clin Oncol. 2016;34:2247-57.

22. Bauml J, Mick R, Zhang Y, Watt CD, Vachani A, Aggarwal C, Evans T, Lange C. Frequency of EGFR and KRAS mutations in patients with non small cell lung cancer by racial background: do disparities exist? Lung Cancer. 2013;81:347-53.

23. Steuer CE, Behera M, Berry L, Kim S, Rossi M, Sica G, Owonikoko TK, Johnson $B E$, Kris MG, Bunn PA, Khuri FR, Garon EB, Ramalingam SS. Role of race in oncogenic driver prevalence and outcomes in lung adenocarcinoma: results from the lung Cancer mutation consortium. Cancer. 2016;122:766-72.

24. Shi Y, Au JS, Thongprasert S, Srinivasan S, Tsai CM, Khoa MT, Heeroma K, Itoh Y, Cornelio G, Yang PC. A prospective, molecular epidemiology study of EGFR mutations in Asian patients with advanced non-small-cell lung cancer of adenocarcinoma histology (PIONEER). J Thorac Oncol. 2014;9:154-62.

25. Shi Y, Li J, Zhang S, Wang M, Yang S, Li N, Wu G, Liu W, Liao G, Cai K, Chen L, Zheng M, Yu P, Wang X, Liu Y, Guo Q, Nie L, Liu J, Han X. Molecular epidemiology of EGFR mutations in Asian patients with advanced nonsmall-cell lung Cancer of adenocarcinoma histology - mainland China subset analysis of the PIONEER study. PLoS One. 2015;10:e0143515.
26. Lee YG, Kim I, Lee E, Bang SM, Kang CH, Kim YT, Kim HJ, Wu HG, Kim YW, Kim TM, Lee KW, Lee SH, Kim DW, Heo DS. Risk factors and prognostic impact of venous thromboembolism in Asian patients with non-small cell lung cancer. Thromb Haemost. 2014;111:1112-20.

27. Verso M, Chiari R, Mosca S, Franco L, Fischer M, Paglialunga L, Bennati C, Scialpi M, Agnelli G. Incidence of Ct scan-detected pulmonary embolism in patients with oncogene-addicted, advanced lung adenocarcinoma. Thromb Res. 2015;136:924-7.

28. Corrales-Rodriguez L, Soulieres D, Weng X, Tehfe M, Florescu M, Blais N. Mutations in NSCLC and their link with lung cancer-associated thrombosis: a case-control study. Thromb Res. 2014;133:48-51.

29. Ades S, Kumar S, Alam M, Goodwin A, Weckstein D, Dugan M, Ashikaga T, Evans M, Verschraegen C, Holmes CE. Tumor oncogene (KRAS) status and risk of venous thrombosis in patients with metastatic colorectal cancer. J Thromb Haemost. 2015;13:998-1003.

30. Chew HK, Davies AM, Wun T, Harvey D, Zhou H, White RH. The incidence of venous thromboembolism among patients with primary lung cancer. J Thromb Haemost. 2008;6:601-8.

31. Blom JW, Osanto S, Rosendaal FR. The risk of a venous thrombotic event in lung cancer patients: higher risk for adenocarcinoma than squamous cell carcinoma. J Thromb Haemost. 2004;2:1760-5.

32. Ogren M, Bergqvist D, Wahlander K, Eriksson H, Sternby NH. Trousseau's syndrome - what is the evidence? A population-based autopsy study. Thromb Haemost. 2006;95:541-5.

33. Numico G, Garrone O, Dongiovanni V, Silvestris N, Colantonio I, Di Costanzo G, Granetto C, Occelli M, Fea E, Heouaine A, Gasco M, Merlano M. Prospective evaluation of major vascular events in patients with nonsmall cell lung carcinoma treated with cisplatin and gemcitabine. Cancer. 2005; 103:994-9.

\section{Ready to submit your research? Choose BMC and benefit from:}

- fast, convenient online submission

- thorough peer review by experienced researchers in your field

- rapid publication on acceptance

- support for research data, including large and complex data types

- gold Open Access which fosters wider collaboration and increased citations

- maximum visibility for your research: over $100 \mathrm{M}$ website views per year

At BMC, research is always in progress.

Learn more biomedcentral.com/submissions 